\title{
A EducaÇão Escolar Quilombola, EducaÇão das RelaÇões ÉtNico-Raciais E PARA o ENSINo de História e Cultura Afro- BRASILEIRA E AFRICANA E A IMPORTÂNCIA DE SUA PRESENÇA NA Base Nacional Comum Curricular (BNCC)
}

The Quilomibola School Education, EThnic and Racial Relations Education AND fOr the Teaching OF AFroBraZilian AND AFrican History AND Culture AND THE IMPORTANCE OF ITS PRESENCE IN THE NATIONAL CURRICULAR COMMON BASE (BNCC)

Stabelecer uma relação permanente, sólida e fecunda entre a educação posto para todos que se preocupam com os rumos da educação em nosso país e o seu papel na afirmação nos direitos humanos e sociais e na consolidação dos valores mais caros à edificação da civilização brasileira.

Ocorre que os problemas se multiplicam, as verbas são insuficientes, quando não, diminuem, e as diferentes etapas de ensino têm sofrido consequências, a saber: a educação infantil malogra em atender os interesses mais elementares da população por vagas nas escolas; o ensino fundamental assiste a escalada dos índices de abandono e a evasão de matrículas, o ensino médio encontra-se mergulhado num pântano 


\section{Cadernos}

A EDUCAÇ̃̃O ESCOLAR QUILOMBOLA, EDUCAÇ̃̃O DAS RELAÇÕES ÉTNICORACIAIS E PARA O ENSINO DE HISTÓRIA E CULTURA AFRO-BRASILEIRA E AFRICANA E A IMPORTÂNCIA DE SUA PRESENÇA NA BASE NACIONAL COMUM CURRICULAR (BNCC)

sombrio e os cursos universitários oferecem padrões duvidosos de qualidade na formação humana e profissional.

Não bastasse esse preocupante cenário, a maioria dos jovens se veem desestimulados e não se interessam em cursar as diferentes licenciaturas, responsáveis pela formação de professores.

Vivemos tempos difíceis no campo educacional e o escasso interesse pela profissão docente faz com que aqueles dedicados ao magistério tenham que se desdobrar na cotidianidade de suas atividades na escola, muitas vezes desassistidos das condições mais elementares para o seu pleno e efetivo exercício da docência e do fortalecimento das relações do processo ensino e aprendizagem.

Não deixa de ser inquietante e até mesmo assustador que essa verdadeira tragédia não seja capaz de comover as autoridades estatais no oferecimento de recursos financeiros, tecnológicos e na permanente valorização da profissão docente em todos os seus níveis como formas de valorização do papel da educação na formação humana, profissional e identitária da sociedade brasileira.

Nesse aspecto, entre outras, as discussões em torno da Base Nacional Comum Curricular (BNCC) assumem grande relevância acadêmica, política e social, tanto pelo seu caráter normativo para o desenvolvimento das diretrizes do trabalho pedagógico cotidiano na escola infantil e no ensino fundamental oferecido pelas redes públicas e particulares; quanto para aqueles que atuam no âmbito da pesquisa acadêmica educacional e que estão preocupados em contribuir com a diminuição das enormes desigualdades que se registram nas relações de ensino e aprendizagem em nosso país. 
No bojo processual e polêmico dessas discussões, em vigência há mais de dez anos, a lei 10639/03 veio dar novo impulso às pesquisas acerca da participação da população afrodescendente na sociedade brasileira, em especial no campo da educação e seus inúmeros desdobramentos. Entre avanços e retrocessos, o tema entrou na agenda política do país e tornou-se um dos assuntos mais debatidos ultimamente, muito em razão de sua capilaridade com outros temas afins, como o racismo, a discriminação, a inclusão social e/ou educacional, o "empoderamento" da população negra etc.

Diante desse quadro, como editores da Revista Cadernos de Pós-graduação, lançamos $a$ proposição de organizarmos o dossiê "Educação Escolar Quilombola, Educação das Relações Étnico-Raciais e para o Ensino de História e Cultura Afro-Brasileira e Africana", com o intuito de debater não apenas o legado da referida lei à atual situação da educação brasileira; mas também os desdobramentos futuros que a "questão étnico-racial" pode suscitar para nossa sociedade ávida de profundas transformações sociais.

Nosso intuito foi o de colaborar com a reflexão e com a compreensão de uma temática que tem profundas raízes históricas de grande importância nos dias atuais; como também deixar registrado a premissa e a compreensão que temos de que a relação que se estabelece entre os currículos que são formulados, apresentados, discutidos e socializados desde a educação infantil, passando pelo ensino fundamental, até alcançar o ensino superior e a formação das identidades na sociedade brasileira é muito grande.

Tal preocupação se funda no reconhecimento da importância da presença de uma rica e crescente diversidade sociocultural, com um sem número de manifestações culturais, religiosas, alimentares, musicais e comportamentais; sem falar das diferenças 


\section{Cadernos}

A EDUCAÇÃO ESCOLAR QUILOMBOLA, EDUCAÇÃO DAS RELAÇÕES ÉTNICORACIAIS E PARA O ENSINO DE HISTÓRIA E CULTURA AFRO-BRASILEIRA E AFRICANA E A IMPORTÂNCIA DE SUA PRESENÇA NA BASE NACIONAL COMUM CURRICULAR (BNCC)

dos fenótipos que também se mostram de grande monta na constituição da fisionomia de nós mesmos!

Os horrores da escravidão e a imposição da cultura europeia que foram impostos as nações indígenas e aos povos africanos ao longo de mais de trezentos anos de história não foram capazes de emudecer e de eliminar os traços culturais e a inestimável herança social de toda essa gente na formação da identidade e no sentido civilizatório do povo brasileiro.

Dito isto, esse número da Revista Cadernos de Pós-Graduação, conta, na seção dossiê, com os seguintes manuscritos: Educação do corpo e relações étnico-raciais sob o olhar de professores, de Kalyla Maroun; Identidade quilombola e educação escolar quilombola: contribuições a partir da experiência de um quilombo, de Sandra Nivia Soares de Oliveira; Currículo multicultural como instrumento de empoderamento de escolas quilombolas, autoria de Marcio Antonio Raiol Santos e Carlos Afonso Ferreira Santos; A formação docente continuada para as relações étnico-raciais no Rio de Janeiro: a experiência do programa de estudo do negro na sociedade brasileira (PENESB/UFF), de Vitor Leandro de Souza, Tiago Dionísio da Silva e Tatiane Pacheco de Mattos; Os saberes e fazeres das crianças quilombolas MarajoaraSalvaterra-Pará, de Erica de Sousa Peres e Nazaré Cristina Carvalho; A lei 10.639/03 e as relações étnico-raciais no ambiente escolar: mudanças e permanências, de Nívea Maria Araújo Santana.

Na seção artigos, a revista comtempla os seguintes manuscritos: A formação de educadores e a educação inclusiva: da sensibilidade ético-política à condição humana, de Marisa Soares; O professor surdo universitário: estudo sobre possíveis estigmas, de Emmanuelle Félix Santos; Desafios e surpresas da inclusão de uma criança cega em sala de aula, de Valquiria Bertuzzi Veronesi e Francisca Eleodora 
Santos Severino; Educação, comunicação e mídia: uma abordagem teórica, de Douglas Branco de Camargo, Iris Weiduschat e Alvin Noriler; Políticas de educação especial: análise do plano de educação (2015 - 2025) e diretrizes da educação especial (2012) de Macapá-AP, de Marcia Maria dos Santos, Maria do Carmo Lobato da Silva e Ilma de Andrade Barleta; Políticas de Inclusão e a realidade profissional: a experiência de uma graduanda cega no estágio curricular supervisionado, de Kalina Salaib Springer, Sabrina Mangrich de Assunção e Yanna D'Angelis de Carvalho Gonçalves; Educação inclusiva, os desafios para sua efetivação, de Carla Campos de Oliveira Almeida.

Esse número da Cadernos também conta com as seguintes resenhas: Temas fundamentais na escola da infância, de Ligia de Carvalho Abões Vercelli e Cristiano Rogério Alcântara (Orgs), escrita por Simone Eliane dos Santos Pessanha; Plano Nacional de Educação: diversos olhares, de Andréia Nunes Militão, Fábio Perboni (Orgs), autoria de Sueli do Nascimento e Welcianne Iris de Queiroz; A educação básica pública tem solução?, de Herman Jacobus Cornelis Voorwald, escrita por Carlos Lima Dantas; A vida cotidiana dos adolescentes em conflito com a lei e o envolvimento com práticas delitivas, de Neusa Francisca de Jesus, escrita por Agnaldo Aparecido Geremias; O retrato histórico da formação inicial do professor no Brasil: inquietudes e ponderações, de Lucilene Pisaneschi, autoria de Raquel Silva Santos.

Boa leitura

Ligia Vercelli

Carlos Baner 